\title{
IMPLEMENTASI PROJECT BASE LEARNING DENGAN KONSEP ECO-GREEN DI SMA IT BAITUL JANNAH BANDAR LAMPUNG
}

\author{
Arlina Phelia'), Galuh Pramita1), Try Susanto1), Agus Widodo'), Agus Tina') \\ 1)Program Studi Teknik Sipil, Fakultas Teknik dan IImu Komputer, Universitas Teknokrat Indonesia, Bandar Lampung, \\ Lampung, Indonesia
}

Corresponding author: Arlina Phelia

E-mail : arlina.phelia@teknokrat.ac.id

Diterima 11 Oktobe 2021, Direvisi 02 November 2021, Disetujui 02 Novemebr 2021

\begin{abstract}
ABSTRAK
Salah satu konsep Iptek yang dapat dikembangkan untuk sekolah adalah dengan berbasis eco-green. Keterkaitan pembelajaran Project Base Learning dengan konsep eco-green ini guna menekankan pada para guru agar dapat meningkatkan model pembelajaran yang lebih relevan. Salah satu permasalahan yang terjadi di sekolah SMA IT Baitul Jannah di masa pandemi ini adalah masih belum maksimalnya pembelajaran secara PjBL. Hal ini perlu adanya peningkatan kualitas dan kuantitas guru maupun siswa dalam bidang pendidikan. Menghadapi tantangan tersebut, guru dituntut untuk menguasai teknologi informasi dan penerapan langsung Iptek. Guru harus mampu memanfaatkan teknologi maupun Iptek dalam melaksanakan proses pembelajaran. Untuk itu tim melakukan kegiatan pengabdian kepada masyarakat berupa pelatihan dan penyuluhan pemanfaatan limbah minyak jelantah yang mana ini merupakan langkah awal dalam menerapkan konsep eco green di sekolah. Metode pengumpulan data yang digunakan adalah wawancara dan survei. Hasil dari kegiatan ini adalah manfaat pengetahuan secara praktikum dalam PjBL mata pelajaran kimia dan peningkatan kreatifitas siswa/i dalam meningkatkan kegiatan praktik mengenai konsep eco green. Hal ini didapatkan peningkatan sebesar $28,58 \%$ menjadi $100 \%$ siswa yang mengetahui manfaat dari limbah domestik yaitu minyak jelantah.
\end{abstract}

Kata kunci: limbah domestik; minyak jelantah; pemberdayaan masyarakat; sabun batang; sekolah

\begin{abstract}
One of the science and technology concepts that can be developed for schools is based on eco-green. The linkage of Project Base Learning with the eco-green concept is to emphasize teachers so that they can improve learning models that are more relevant. The problem that occurred at the Baitul Jannah High School during this pandemic was that PjBL learning was still not maximal. This requires an increase in the quality and quantity of teachers and students in education. In these challenges, teachers are required to master information technology and direct application of science and technology. Teachers must be able to utilize technology and science in carrying out the learning process. For this reason, the team carried out community service activities in the form of training and counseling on the use of used cooking oil waste, which is the first step in implementing the eco-green concept in schools. The methods used are interviews and surveys. The results of this activity are the benefits of practical knowledge in PjBL chemistry subjects and increasing students' creativity in increasing practical activities regarding the eco-green concept. This resulted in an increase of $28,58 \%$ to $100 \%$ of students who knew the benefits of domestic waste.
\end{abstract}

Keywords: domestic waste; used cooking oil; community development; bar soap; school

\section{PENDAHULUAN}

Lingkungan Sekolah SMA IT Baitul Jannah secara teritorial masuk ke dalam wilayah Kota Bandar Lampung. Pada kondisi di masa pandemi covid-19 ini siswa/i di SMA IT Baitul Jannah banyak yang melakukan aktifitasnya di dalam rumah. Salah satu hal yang dilakukan para guru-guru adalah dengan meningkatkan kualitas dan kuantitas dalam bidang pendidikan kepada siswa/i. Perkembangan teknologi memaksa berbagai pihak untuk dapat mengikuti semua dan dapat berjalan dengan baik. Tidak terkecuali dalam pengembangan konsep eco-green di sekolah yang mana saat ini para siswa/i masih belum produktif dalam mengembangkan konsep tersebut, dan ditambah lagi dengan kondisi pandemi covid-19 yang mengharuskan siswa/i harus belajar dari rumah. Menghadapi tantangan tersebut, guru selaku fasilitator dituntut dapat memilih media pembelajaran yang tepat (Pathoni dkk, 2019). 
Guru juga harus mampu memanfaatkan teknologi maupun Iptek dalam melaksanakan proses pembelajaran. Berkaitan dengan hal tersebut indikator dalam mengembangkan model pembelajaran yang diharapkan tepat dan sesuai untuk mengarah pada hal-hal pembelajaran Project Base Learning (Lubis, 2018).

Pembelajaran merupakan suatu sistem atau proses membelajarkan pembelajar yang direncanakan, dilaksanakan, dan dievaluasi secara sistematis agar pembelajar dapat mencapai tujuan-tujuan pembelajaran secara efektif dan efisien (Komalasari, 2013). Salah satu model pembelajaran Iptek yang dapat dikembangkan untuk sekolah dengan berbasis eco-green. Keterkaitan pembelajaran Project Base Learning dengan konsep eco-green ini guna menekankan pada para guru agar dapat meningkatkan model pembelajaran yang lebih relevan.

Salah satu dampak yang mengalami peningkatkan disekolah adalah penggunaan minyak goreng. Pada kondisi pandemi ini kantinkantin sekolah yang beroperasi hanya sebagian, namun sisa proses penggorengan tersebut yang terbuang akan mengalami dampak yang berbahaya di sekolah. Potensi limbah minyak jelantah menjadi sangat besar karena belum maksimal penggunaannya sehingga dapat menjadi air limbah domestik (Ginting dkk, 2020).

Penanganan yang tepat agar limbah minyak goreng bekas ini dapat bermanfaat dan tidak menimbulkan kerugian dari aspek kesehatan manusia dan lingkungan sekolah, yaitu dengan cara mengubahnya secara proses kimia menjadi sabun (Septiowati dkk, 2019). Pada kondisi penanganan ini diharapkan siswa/i maupun guru dapat berinovasi dan berkreatifitas dalam meningkatkan Iptek Project Base Learning (PjBL) di sekolah. Kegiatan PjBL merupakan model pembelajaran yang mendukung siswa dalam pencapaian prestasi belajar serta penguasaan kemampuan siswa dalam menyelesaikan permasalahan di dunia nyata.

Konsep eco-green dalam penerapan di PjBL dapat dilakukan dalam pembelajaran Biologi maupun Kimia (IPA) di tingkat SMA seperti pada materi pokok pencemaran dan pemanfaatan lingkungan. Berdasarkan Permendikbud Nomor 24 tahun 2016, dilakukan untuk menganalisis data perubahan lingkungan, penyebab, dan dampaknya bagi kehidupan serta merumuskan gagasan pemecahan masalah perubahan lingkungan yang terjadi di lingkungan sekitar. Salah satu langkah antisipasi yang paling dasar ialah mengubah perilaku seseorang dengan mengupayakan langkah dan sikap untuk mengurangi dampak global warming tersebut yaitu dengan menanamkan sikap cinta lingkungan bagi anak didik sedini mungkin melalui lembaga pendidikan di lingkungan sekolah (Amareta dkk, 2017).

Berbagai permasalahan lingkungan khususnya di Kota Bandar Lampung yang sering terjadi seperti pencemaran limbah cair, limbah padat, tidak berjalannya sumur resapan dan lainnya. Permasalahan secara regional maupun global ini dapat dijadikan sebagai sumber belajar untuk biologi maupun kimia. Pendidikan sains diarahkan untuk mencari tahu dan berbuat sehingga dapat membantu siswa untuk memperoleh pemahaman yang lebih mendasar tentang alam sekitar. Dari hal tersebut kita dapat menciptakan produk-produk atau inovasi dengan konsep eco-green yang mempunyai nilai estetika dan kesediaan bahan baku yang mudah didapat, murah akan tetapi hasilnya menjadi berkualitas. Kegiatan ini dapat dilakukan di skala Pendidikan (sekolah) dan meningkatkan inovasi maupun pembelajaran secara aplikatif.

Beberapa penelitian terkait eco-green seperti minyak goreng bekas menjadi berbagai diversifikasi produk sudah banyak dilakukan. Salah satunya tentang upaya pemanfaatan limbah minyak goreng bekas untuk diolah menggunakan rekayasa proses menjadi produk yang lebih berguna berupa sabun mandi (Prihanto \& Irawan, 2018). Oleh karena itu solusi dari permasalahan mitra yang telah disepakati adalah melakukan kegiatan pelatihan dan penyuluhan melalui pemanfaatan limbah minyak jelantah menjadi sabun sebagai upaya pengendalian lingkungan pencemaran limbah domestik. Selain itu pengabdian ini akan memberikan edukasi maupun penerapan dalam PjBL mengenai konsep eco-green di Sekolah SMA IT Baitul Jannah Bandar Lampung dan bagaimana meningkatkan sistem informasi dalam Project Base Learning di masa pandemi covid-19.

\section{METODE}

Metode yang digunakan dalam kegiatan ini meliputi pendekatan individual dan partisipatif. Pendekatan individual dilakukan dengan berkomunikasi secara langsung yang mana hal ini dilakukan untuk mengetahui kebutuhan yang diperlukan oleh mitra terkait permasalahan yang mitra hadapi yakni terkait pembelajaran project base learning. Untuk pendekatan secara partisipatif dilakukan guna melibatkan peserta PKM yaitu dalam pelatihan pemanfaatan limbah minyak jelantah menjadi sabun kepada siswa/i SMA IT Baitul Jannah. Pelaksanaan kegiatan PKM ini dilakukan empat tahapan yaitu tahapan persiapan, tahapan sosialisasi, tahapan 
pelatihan, dan tahapan evaluasi yang dapat dilihat pada gambar 1.

Tahapan Persiapan :

1. Koordinasi dengan pihak sekolah SMA IT Baitul Jannah.

2. Menganalisa kebutuhan dan merumuskan permasalahan tentang PjBL.

Tahapan Sosialisasi :

1. Mempersiapkan materi pembelajran kimia PjBL konsep eco-green.

2. Merencanakan pelatihan limbah minyak jelantah dan penyuluhan lain.

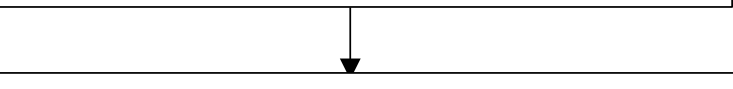

Tahapan Pelatihan :

1. Pelatihan kepada siswa dalam praktik pembuatan sabun dari minyak jelantah.

2. Penyuluhan bahaya dan manfaat dari limbah minyak jelantah.

Tahapan Evaluasi :

Evaluasi review dari pelatihan pembuatan sabun dari minyak jelantah.

Gambar 1. Tahapan Pelaksanaan Kegiatan Pengabdian Kepada Masyarakat.

Pelaksanaan kegiatan pelatihan dilakukan di SMA IT Baitul Jannah Bandar Lampung, yang dilakukan pada tanggal 9 April 2021 dengan pendekatan partisipatif kepada para peserta. Kegiatan penyuluhan dan pelatihan ini dilaksanakan pada tanggal 31 Maret - 12 April 2021 dihadiri oleh siswa/i, guru-guru, dan Kepala Sekolah SMA IT Baitul Jannah dengan total siswa/i 21 orang.

Metode pelaksanaan yang digunakan dalam kegiatan ini memiliki empat tahapan: (a) tahap persiapan untuk melakukan koordinasi dengan mitra terkait identifikasi permasalahan. (b) Tahap sosialisasi mempersiapkan materi pentingnya pegetahuan terkait pengendalian dampak lingkungan dari bahaya limbah minyak jelantah. (c) Tahap pelatihan pembuatan sabun batang menggunakan bahan minyak jelantah untuk memberikan informasi dan keterampilan kepada peserta. (d) Tahap evaluasi diberikan untuk mendapatkan respon serta peran aktif peserta selama pelatihan.

Pelatihan kepada mitra diprioritaskan untuk memberikan pengetahuan secara praktik dalam pemanfaatan limbah minyak jelantah pada masa pandemi covid-19 serta memberikan informasi dan memotivasi peserta terkait pengetahuan tentang manfaat limbah minyak jelantah yang terolah dengan baik.

\section{HASIL DAN PEMBAHASAN}

Pelaksanaan pengabdian masyarakat dilaksanakan pembuatan bahan campuran untuk praktik awal terlebih dahulu oleh tim pelaksana dan mensosialisasikan kepada mitra terkait pelatihan yang akan dilakukan. Para peserta yang belum mengetahui cara mengolah limbah minyak jelantah menjadi bahan produk yang bermanfaat. Hal ini menjadi dasar pembelajaran secara praktik kimia project base learning dengan memafaatkan limbah minyak jelantah dan soda api $(\mathrm{NaOH})$.

Para peserta siswa/i diberikan penyuluhan tentang pentingnya pengolahan minyak jelantah guna mengurangi dampak negatif ke lingkungan yang mana memberikan respon positif dengan mengungkapkan beberapa kendala dan kesulitan yang mereka hadapi untuk memperoleh lingkungan yang bersih sehingga terhindar dari bahaya kesehatan yang buruk. Survey yang telah dilakukan sebelumnya di sekolah didapatkan bahwa belum adanya pengolahan yang baik terkait limbah domestik. Hal ini terlihat bahwa limbah minyak jelantah yang ada di kantin-kantin sekolah langsung dibuang ke tanah atau ke saluran drainase saat sebelum pandemi. Sedangkan pada kondisi pandemi area kantin tutup dan tidak ada aktifitas di sekolah, yang menyebabkan terjadi penurunan limbah domestik. Hal ini apabila tidak ada peningkatan dalam pengolahan limbah domestik, akan membahayakan lingkungan disekitar. Oleh sebab itu para siswa/i perlu adanya pembelajaran baru secara praktik dalam meningkatkan pengetahuannya mengenai konsep eco-green, yang mana memanfaatkan limbah minyak jelantah menjadi sabun batangan.

Sosialisasi awal yang dilakukan adalah mempersiapkan bahan baku pembuatan sabun dan prosedur modul pembuatan sabun mendemonstrasikan prosedur pembuatan sabun. Peserta (siswa) dapat mengikuti langsung setiap tahapan pembuatan sabun dengan menggunakan bahan-bahan yang telah dipersiapkan oleh tim pelaksana. Hasil yang diharapkan dari pemanfaatan limbah minyak jelantah ini adalah dapat diolah menjadi sabun batang cuci yang dapat dipergunakan untuk mencuci peralatan rumah tangga, keset, kain lap, dan lainnya. Kegiatan peyuluhan dan praktik secara langsung ini menjadi salah satu point utama dalam project base learning dibidang pelajaran kimia. Sesuai dengan kondisi dan permasalahan di sekolah, bahwa guru-guru ingin meningkatkan kegiatan $\mathrm{PjBL}$ yang saat ini masih dilakukan secara online. 
Kegiatan praktik memang tidak dilakukan seluruhnya kepada siswa/i, namun perwakilan siswa/i yang hadir inilah menjadi pemicu untuk dapat meningkatkan keingintahuan dan wawasan dalam hal praktik PjBL. Para siswa/i antusias dalam sosialisasi pentingnya pengolahan minyak jelantah ini, serta respon guru-guru yang sangat baik dalam meningkatkan pengetahuannya di bidang ecogreen. Kegiatan sosialisasi ini dapat dilihat pada gambar 2 berikut ini.

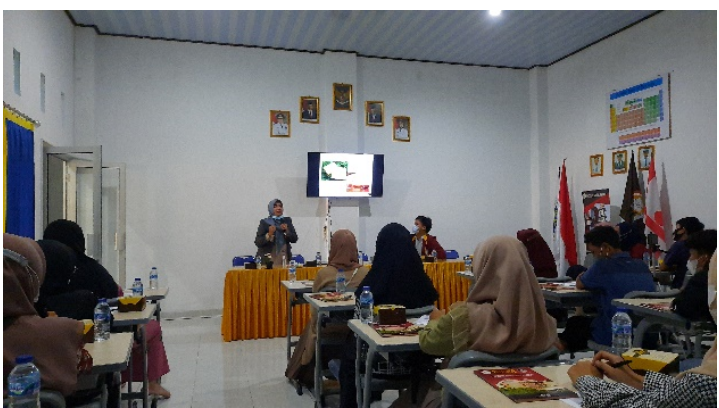

Gambar 2. Kegiatan Sosialisasi dalam pengendalian limbah minyak jelantah.

Dari kegiatan penyuluhan ini selanjutnya dilakukan pelatihan langsung cara pembuatan sabun batangan dari minyak jelantah kepada para siswa/i SMA IT Baitul Jannah. Pelatihan ini dilakukan pada tanggal 9 April 2021, yang dilakukan secara offline dengan mematuhi semua protokol kesehatan. Praktikum ini diharapkan mampu meningkatkan pemahaman dan wawasan siswa/i mengenai PjBL pelajaran kimia, dimana proses pembuatan sabun menjadi minyak jelantah salah satunya adalah memberikan soda api $(\mathrm{NaOH})$ dengan kadar rendah yakni $40 \%$. Secara hidrolisis minyak merupakan asam karboksilat (asam lemak) dan gliserol, dasar teoritis dari pembuatan sabun ini adalah pencampuran asam lemak dan basa kuat $(\mathrm{NaOH})$ sehingga menghasilkan sabun berupa garam natrium dari asam lemak/minyak. Soda api $(\mathrm{NaOH})$ digunakan untuk membuat sabun padat yang mana sabun memiliki sifat membersihkan melalui proses kimia koloid, karena sabun mempunyai gugus polar dan nonpolar. Selain itu, sebelum dilakukan pencampuran, minyak jelantah mula-mula dilakukan pemurnian dengan arang aktif tumbuk atau merendam dengan bahan alami seperti jahe dan rendam dalam minyak jelantah sehari sebelumnya dan kemudian disaring guna mendapatkan minyak jelantah yang lebih jernih. Dalam mencampurkan air dan soda api tidak boleh terbalik diharuskan soda api yang dituangkan ke dalam wadah berisi air agar tidak terjadi kesalahan yang tidak diinginkan. Untuk hasil sabun dilakukan proses curing selama 2-3 bulan. Proses pembuatan ini disajikan pada gambar 3.

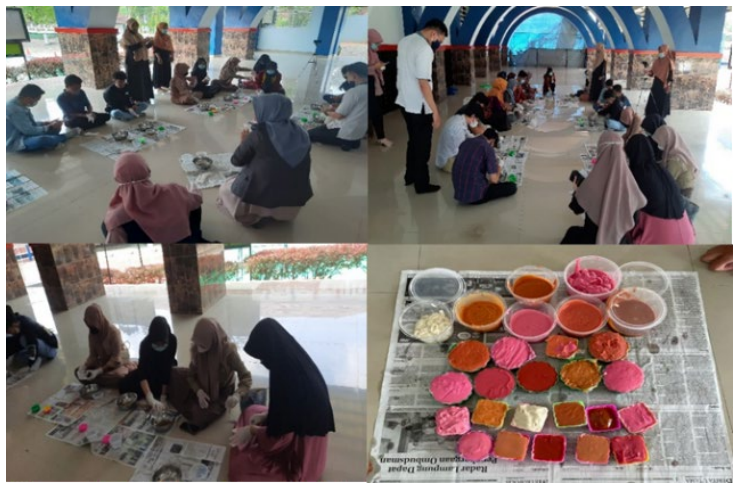

Gambar 3. Kegiatan Pemberian Pelatihan

Pebuatan Sabun dari Minyak Jelantah.

Hasil dari evaluasi kegiatan pelatihan para siswa/i yang dilaksanakan di sekolah sangat antusias dengan kegiatan PKM ini, karena kegiatan ini bermanfaat bagi sekolah dan pengembangan pembelajaran project base learning bagi guru maupun murid. Berdasarkan hasil evaluasi dalam pengisian kuesioner review pengembangan konsep eco green yang diberikan sebelum dan sesudah didapatkan bahwa terdapat peningkatan pengetahuan siswa/i yang dapat dilihat pada tabel 1 sebagaimana menjadi tolak ukur dalam pengembangan $\mathrm{PjBL}$.

Tabel 1. Hasil Evaluasi Kegiatan PKM

\begin{tabular}{|c|c|c|c|c|c|}
\hline \multirow[t]{2}{*}{ No } & \multirow[t]{2}{*}{ Pertanyaan } & \multicolumn{2}{|c|}{ Sebelum } & \multicolumn{2}{|c|}{ Sesudah } \\
\hline & & $\mathrm{Ya}$ & Tidak & $\mathrm{Ya}$ & Tidak \\
\hline 1. & $\begin{array}{l}\text { Pengetahuan } \\
\text { anda mengenai } \\
\text { pengolahan } \\
\text { minyak jelantah } \\
\text { menjadi sabun? }\end{array}$ & 4 & 17 & 21 & 0 \\
\hline 2. & $\begin{array}{l}\text { Apakah anda } \\
\text { sebelumnya } \\
\text { mengetahui } \\
\text { minyak jelantah } \\
\text { dapat digunakan } \\
\text { sebagai bahan } \\
\text { dasar pembuatan } \\
\text { sabun cuci } \\
\text { piring? }\end{array}$ & 0 & 21 & 21 & 0 \\
\hline 3. & $\begin{array}{ll}\text { Apakah anda } \\
\text { berminat } \\
\text { membuat sabun } \\
\text { dari minyak } \\
\text { jelantah sendiri } \\
\text { dari rumah? }\end{array}$ & 0 & 21 & 21 & 0 \\
\hline 4. & $\begin{array}{l}\text { Apakah anda } \\
\text { paham tata cara } \\
\text { pembuatan } \\
\text { sabun dari } \\
\text { minyak jelantah } \\
\text { berdasarkan dari }\end{array}$ & 2 & 19 & 21 & 0 \\
\hline
\end{tabular}




\begin{tabular}{|c|c|c|c|c|c|}
\hline \multirow[t]{3}{*}{ No } & \multirow[t]{2}{*}{ Pertanyaan } & \multicolumn{2}{|c|}{ Sebelum } & \multicolumn{2}{|c|}{ Sesudah } \\
\hline & & $\mathrm{Ya}$ & Tidak & $\mathrm{Ya}$ & Tidak \\
\hline & $\begin{array}{ll}\text { modul yang } \\
\text { diberikan? }\end{array}$ & & & & \\
\hline 5. & $\begin{array}{l}\text { Apakah kegiatan } \\
\text { praktikum ini } \\
\text { menambah } \\
\text { wawasan anda } \\
\text { dalam } \\
\text { pembelajaran } \\
\text { project base } \\
\text { learning? }\end{array}$ & 4 & 17 & 21 & 0 \\
\hline 6. & $\begin{array}{lr}\text { Apakah } & \text { anda } \\
\text { berminat } & \text { untuk } \\
\text { membuat } & \\
\text { kegiatan } & \\
\text { praktikum } & \\
\text { dirumah } & \text { dengan } \\
\text { konsep } & \text { eco } \\
\text { green? } & \\
\end{array}$ & 8 & 13 & 21 & 0 \\
\hline 7. & $\begin{array}{l}\text { Apakah anda } \\
\text { mengetahui } \\
\text { manfaat dari } \\
\text { limbah minyak } \\
\text { jelantah? }\end{array}$ & 2 & 19 & 21 & 0 \\
\hline 8. & $\begin{array}{l}\text { Apakah anda } \\
\text { mengetahui } \\
\text { bahaya dari } \\
\text { limbah minyak } \\
\text { jelantah apabila } \\
\text { tidak diolah } \\
\text { dengan baik? }\end{array}$ & 4 & 17 & 21 & 0 \\
\hline & Nilai Total & 24 & 144 & 168 & 0 \\
\hline & Persentase & 71 & $41 \%$ & & \\
\hline
\end{tabular}

Sumber : Hasil Analisis, 2021

Dari tabel 1 terlihat bahwa sebanyak $71,41 \%$ menyatakan bahwa belum mengetahui dengan jelas manfaat dari limbah minyak jelantah. Sedangkan yang lainnya sudah mengetahui namun belum mengetahui tata cara pembuatan limbah minyak jelantah menjadi sabun. Setelah dilakukan pelatihan dan penyuluhan tentang manfaat dari minyak jelantah menjadi sabun, seluruh peserta $100 \%$ menyatakan dapat mengetahui dan memahami tentang manfaat limbah minyak jelantah tersebut. Dari hal tersebut tampak adanya peningkatan pengetahuan sebesar 28,58\%, sehingga dapat dinyatakan kegiatan bermanfaat bagi peserta siswa/i dalam pelatihan praktikum membuat sabun dari minyak jelantah sebagai motivasi dalam meningkatkan project base learning.

\section{SIMPULAN DAN SARAN Simpulan}

Berdasarkan hasil kegiatan PKM yang telah dilakukan oleh tim pelaksana, maka dapat disimpulkan bahwa penyuluhan dalam pemanfaatan minyak jelantah menjadi sabun bermanfaat bagi mitra dalam meningkatkan minat dan kreativitas siswa/i dalam pembelajaran praktik dan meningkatkan inovasi apa saja yang dapat guru-guru berikan kedepannya dalam project base learning dimasa pandemi. Hal ini juga dapat memicu kegiatan kewirausahaan siswa/i terhadap produk-produk olahan yang ramah lingkungan di sekolah. Hasil evaluasi dari peserta terdapat peningkatan yang cukup signifikan terkait pemanfaatan limbah minyak jelantah menjadi olahan sabun batang.

\section{Saran}

Kegiatan praktik dan pembelajaran dalam pemanfaatan limbah minyak jelantah menjadi sabun batangan dapat digunakan sebagai Project Base Learning disekolah. Penerapan pembelajaran yang termasuk dalam $\mathrm{PjBL}$ ini adalah mata pelajaran kimia. Pengabdian kepada masyarakat yang akan dating dapat dilakukan kegiatan pelatihan praktikum kepada guru-guru maupun siswa/i dibidang mata kuliah lainnya, guna meningkatkan pengetahuan dan inovasi kedepannya dalam PjBL.

\section{UCAPAN TERIMAKASIH}

Author mengucapkan terima kasih kepada Universitas Teknokrat Indonesia, Lampung yang telah mendanai keberlangsungan pengabdian kepada masyarakat ini.

\section{DAFTAR RUJUKAN}

Amareta, D. I., Putra, D. S. H., \& Roziqin, M. C. (2017). Pendampingan Program Eco Green School di Sekolah Menengah Kejuruan Al-Badri Kalisat Kabupaten Jember. Prosiding.

Ginting, D., Wirman, S. P., Fitri, Y., Fitrya, N., Retnawaty, S. F., \& Febriani, N. (2020). PKM Pembuatan Sabun Batang Dari Limbah Minyak Jelantah Bagi IRT Kelurahan Muara Fajar Kota Pekanbaru. Jurnal Pengabdian UntukMu NegeRI, 4(1), 74-77.

Komalasari, Kokom. (2013). Pembelajaran Kontestual: Konsep dan Aplikasi. Bandung: PT Refika Adiatama.

Lubis, F. A. (2018). Upaya Meningkatkan Kreativitas Siswa Melalui Model Project Based Learning. PeTeKa, 1(3), 192201.

Pathoni, H., Pujaningsih, F. B., Hendri, M., Maison, M., \& Nehru, N. (2019). Pelatihan Pengembangan Content ELearning Untuk Guru IPA SEJALUKO. SELAPARANG Jurnal Pengabdian Berkemajuan, 3(1), 120-123. 
Prihanto, A., \& Irawan, B. (2018). Pemanfaatan Minyak Goreng Bekas Menjadi Sabun Mandi. Metana, 14(2), 55-59.

Septiowati, R., Oktavianna, R., Saputri, S. W., Sari, S., \& Benarda, B. (2019). Pemanfaatan Minyak Jelantah Menjadi Sabun Cuci Pada Bank Sampah Di Kelurahan Bambu Apus

Pamulang. Abdimisi, 1(1), 10-17. 